\title{
APLIKASI PROGRAM MATLAB UNTUK ANALISA CITRA HYPERSPECTRAL PADA AKAR DARI TANAMAN KELAPA SAWIT YANG MENGALAMI KEKURANGAN AIR
}

\author{
Mailestari Wina Yance ${ }^{1}$, Minarni $^{1^{*}}$, Feri Candra ${ }^{2}$, Herman $^{3}$ \\ ${ }^{1}$ Jurusan Fisika FMIPA Universitas Riau \\ ${ }^{2}$ Jurusan Teknik Elektro FT Universitas Riau \\ ${ }^{3}$ Jurusan Biologi FMIPA Universitas Riau \\ *E-mail korespondensi: minarni@unri.ac.id
}

\begin{abstract}
Hyperspectral images are three dimensional images which have two dimension spatial information and one dimension spectral information. Hyperspectral image processing using Matlab program is preferable because it is more adaptive for many analysis purposes. This research was aimed to construct Matlab to process and analyze the hyperspectral images of the roots of oil palm plants that have experienced water deficiency. The program was designed and constructed using a GUI. The use of a GUI aims to combine each pixel of the same line from each sample to produce a new image. The samples were roots of oil palm plants that experienced simulated water deficiency by giving different water volumes of $0 \mathrm{~mL}, 1000 \mathrm{~mL}, 2000 \mathrm{~mL}$ and $3000 \mathrm{~mL}$ (normal). The optical method used in this study is a hyperspectral imaging method which has $650 \mathrm{~nm}$ diode laser as the light source, spectrograph Specim Imspector V1O, and a monochrome CMOS as a detector. Reflectance intensity versus wavelength was extracted from each images and analyzed. The results showed that the Matlab GUI program that had been constructed was able to produce 1024 new images that had a pixel size of $15 \times$ 1280 from each sample. The results also show that the reflectance intensity values are higher at higher water deficiency of the oil palm roots.
\end{abstract}

Keywords : Hyperspectral imaging, Laser induced, Oil palm root, Water deficiency, Matlab

\begin{abstract}
ABSTRAK
Citra hiperspektral adalah citra tiga dimensi yang terdiri dari dua dimensi informasi spasial dan satu dimensi informasi panjang gelombang. Pengolahan dan analisa citra hiperspektral mengunakan matlab lebih disukai karena lebih adaptif dibanding program yang tersedia online. Penelitian ini bertujuan untuk membuat program Matlab untuk pengolahan citra hiperspektral yang diinduksi cahaya laser pada akar dari tanaman kelapa sawit yang mengalami kekurangan air. Program dirancang dan dibuat menggunakan GUI. Penggunaan GUI bertujuan untuk menggabungkan setiap piksel garis yang sama dari satu sampel citra sehingga menghasilkan citra baru. Sampel adalah tanaman kelapa sawit yang mengalami kekurangan air yang disimulasi dengan pemberian volume air yang berbeda yaitu $0 \mathrm{~mL}$, $1000 \mathrm{~mL}, 2000 \mathrm{~mL}$ dan $3000 \mathrm{~mL}$ (normal). Metode optik adalah metode pencitraan hiperspektral dengan sumber cahaya berupa laser dioda $650 \mathrm{~nm}$, Spektograf Specim Imspector V10 serta kamera CMOS monokrom sebagai detektor. Hasil dari pengolahan citra hiperspektral berupa intensitas reflektansi terhadap panjang gelombang. Hasil penelitian menunjukkan bahwa program GUI Matlab yang telah dibuat menghasilkan citra baru sebanyak 1024 citra yang memiliki ukuiran piksel $15 \times 1280$ dari satu sampel. Hasil juga menunjukkan intensitas reflektansi dari citra akar terkecil pada akar yang mengalami kekurangan air lebih besar.
\end{abstract}

Kata kunci : Pencitraan Hyperspectral, Induksi laser, Akar pohon kelapa sawit, Kekurangan air, Matlab

Diterima 04-09-2019 | Disetujui 30-09-2019| Dipublikasi 31-10-2019 


\section{PENDAHULUAN}

Matlab atau yang dikenal dengan Matrix Laboratory merupakan bahasa tingkat tinggi (high-performance) dan interaktif yang memiliki elemen data dalam suatu array yang memungkinkan untuk melakukan komputasi secara intensif. Sebuah sistem pada Matlab tersusun dari 5 bagian utama yang mempunyai fungsi yang berbeda. Citra pada program Matlab dikenal sebagai matriks yang memberikan representasi spasial dari suatu objek dalam bidang dua dimensi yang biasanya ditulis dalam koordinat kartesian $(\mathrm{x}, \mathrm{y})$, dan setiap koordinat merepresentasikan satu sinyal terkecil dari objek yang disebut sebagai piksel [1].

Matlab merupakan salah satu program pengolahan citra. Pengolahan citra bertujuan untuk memperoleh informasi yang dibutuhkan dari suatu citra. Pengolahan citra biasanya digunakan untuk meningkatkan kualitas visual atau menonjolkan beberapa aspek informasi yang terkandung dalam citra. Dalam metode Hyperpsectral Imaging, Program Matlab dapat digunakan untuk mengolah citra Hyperpsectral sehingga menghasilkan nilai intensitas reflektansi versus panjang gelombang.

Salah satu metode optik yang dapat mendeteksi sifat internal suatu materi adalah metode Hyperspectral Imaging (HI) [2]. Metode ini merupakan pengabungan metode pencitraan digital dan spektroskopi. Sistem terdiri dari sumber cahaya, spektograf, dan detektor. Spektograf merupakan komponen optik yang berfungsi untuk menguraikan cahaya menjadi spektrum warna. Detektor berfungsi untuk merekam gambar objek [3]. Salah satu metode HI yang telah dikembangkan adalah untuk memprediksi kandungan gula dalam melon [4].

Tanaman kelapa sawit adalah tanaman perkebunan yang mempunyai perakaran dangkal yang menyebabkan tanaman kelapa sawit ini toleran terhadap tekanan atau stress. Stress yang terjadi pada tanaman kelapa sawit didefinisikan sebagai kondisi lingkungan yang menyebabkan berkurangnya produktivitas hasil panen tanaman kelapa sawit [5]. Biasanya stress yang terjadi pada tanaman kelapa sawit berupa stress kekeringan atau kekurangan air. Stress ini terjadi karena ketersediaan air yang berada didalam tanah tidak mencukupi dan proses transpirasi berlangsung secara berlebihan [6].

Kebutuhan air pada tanaman kelapa sawit pada dasarnya berbeda-beda dalam setiap fase pertumbuhan. Banyaknya volume dan frekuensi penyiraman air pada tanaman kelapa sawit dapat berdasarkan kepada umur tanaman kelapa sawit tersebut. Tanaman kelapa sawit yang berumur $0-3$ bulan membutuhkan jumlah air setiap hari perbibit sebanyak 1 liter, untuk tanaman kelapa sawit yang berumur 3 6 bulan sebanyak 2 liter, sedangkan tanaman kelapa sawit yang berumur $6-12$ bulan membutuhkan air sebanyak 3,0 liter per bibit setiap harinya [7]. Tanaman kelapa sawit yang mendapatkan air kurang dari batas normalnya maka tanaman kelapa sawit tersebut akan mengalami penghambatan pertumbuhan dan reproduktivitas..

Pada penelitian ini, GUI Matlab digunakan untuk menggabungkan setiap piksel baris dari setiap citra sampel akar tanaman kelapa sawit sehingga diperoleh citra baru. Citra tersebut kemudian diolah dengan program Matlab sehingga diperoleh nilai intensitas reflektansi maksimum. Perbedaan intensitas reflektansi untuk setiap perlakuan penambahan variasi volume air pada proses penyiraman tanaman kelapa sawit dianalisa.

\section{METODE PENELITIAN}

Metode optik yang digunakan pada penelitian ini adalah metode Hyperspectral Imaging (HI) yang diinduksi cahaya laser. Metode ini digunakan pada akar tanaman untuk mendeteksi tingkat kekurangan air pada tanaman kelapa sawit. Alat yang digunakan terdiri dari sumber cahaya berupa laser dioda 
$650 \mathrm{~nm}$, spektograf Specim Imspector V10, dan kamera CMOS monokrom yang menghasilkan citra dengan ukuran piksel $1024 \times 1280$. Ukuran piksel yang dihasilkan oleh citra tersebut mempunyai arti bahwa citra terdiri dari 1024 baris dan 1280 kolom. Sistem berada pada kotak hitam kedap cahaya luar berukuran $60 \mathrm{~cm}$ x $60 \mathrm{~cm}$ x $90 \mathrm{~cm}$.

Sampel yang digunakan dalam penelitian ini adalah akar tanaman kelapa sawit varietas Tenera yang sudah mengalami tingkat kekurangan air yang ditunjukkan pada Gambar 1.

Gambar 1. merupakan sampel akar dari tanaman kelapa sawit yan telah mendapatkan perlakuan penyiraman air dengan volume berbeda. Tingkat kekurangan air pada tanaman kelapa sawit diwakili oleh variasi pemberian volume air yang terdiri dari $0 \mathrm{~mL}$ (tanpa pemberian air), $1000 \mathrm{~mL}, 2000 \mathrm{~mL}$, dan $3000 \mathrm{~mL}$ (normal).

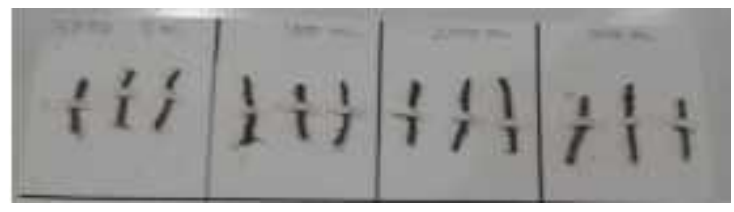

Gambar 1. Sampel akar tanaman kelapa sawit

Perlakukan variasi volume air dilakukan selama 21 hari. Setiap perlakuan mempunyai 3 bibit tanaman sawit yang berumur 8 bulan sehingga sampel terdiri dari 12 bibit. Tananaman kelapa sawit yang mendapatkan pemberian $0 \mathrm{~mL}$ berarti tidak disiram selama 21 hari, pemberian air dengan volume 1000 $\mathrm{mL}$ dan $2000 \mathrm{~mL}$ dilakukan satu kali seminggu. Sedangkan pemberian air $3000 \mathrm{~mL}$ atau normal dilakukan setiap hari. Sebelum diberi perlakuan setiap bibit tanaman kelama sawit mendapatkan perlakuan yang sama selama dua minggu yaitu penyiraman normal $3000 \mathrm{~mL}$ perhari setelah dipindahkan dari polibag kecil ke masing-masing polibag besar berdiameter $40 \mathrm{~cm}$ dan tinggi $25 \mathrm{~cm}$.

Proses perekaman citra pada tanaman kelapa sawit dilakukan pada hari ke-21. Setiap satu variasi volume diambil tiga akar primer masing-masing dari setiap bibit sehingga diperoleh tiga akar untuk setiap perlakuan, Akar-akar tersebut kemudian dibersihkan dan diukur diameter serta panjangnya. Akar kemudian diletakkan di atas translation stage di dalam kotak yang telah tersedia. Setiap sampel akar mempunyai 15 citra yang diambil dengan merekam satu citra garis per $2 \mathrm{~mm}$ perpindahan translation stage sehingga keseluruhan akar dapat di scan.

Program Matlab digunakan untuk mengolah citra hyperspectral akar yang diperoleh. Gambar 2 menunjukkan flowchart dari program Matlab yang dibuat.

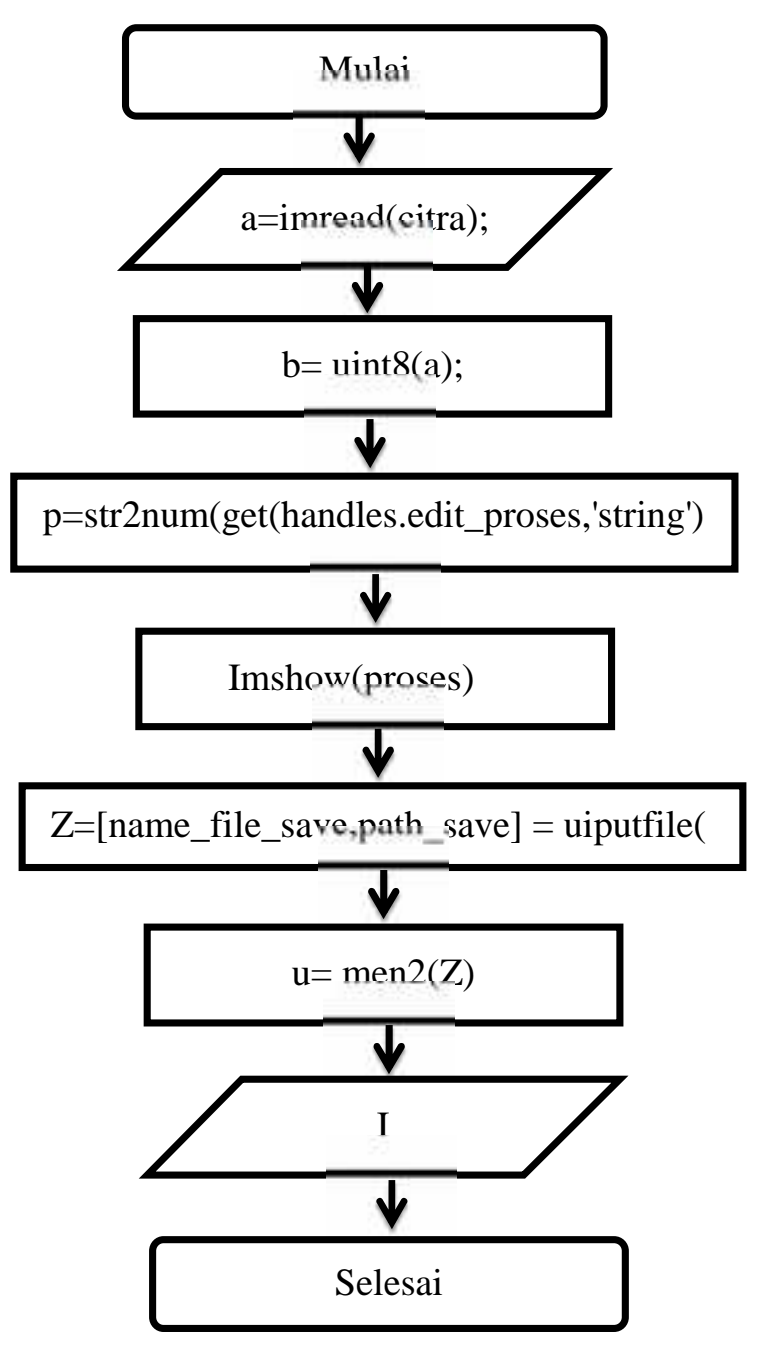

Gambar 2. Flowchart program Matlab

Penggunaan program GUI Matlab pada penelitian ini berfungsi untuk menggabungkan setiap piksel baris dari setiap 15 citra dari satu sampel akar yang diperoleh sehingga 
menghasilkan citra baru. Citra yang dihasilkan tersebut kemudian ditentukan nilai intensitasnya. Terdapat beberapa tahapan dalam proses pengolahan citra. Tahapan pertama dalam pengolahan citra adalah menggabungkan setiap ukuran piksel dari 15 citra yang diperoleh dari sumber cahaya yang digunakan. Proses penggabungan ini menggunakan program GUI Matlab yang berhasil dibuat yang ditunjukkan seperti pada Gambar 3.

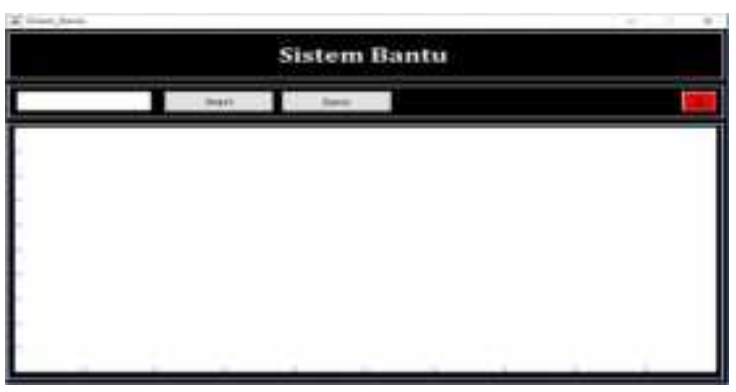

Gambar 3. Tampilan program GUI Matlab

Tahapan berikutnya dalam proses pengolahan citra pada penelitian ini adalah mengkalibrasi setiap ukuran piksel baris ke panjang gelombang. Proses pengkalibrasian ini menggunakan sumber cahaya laser dioda merah $650 \mathrm{~nm}$ dan laser dioda ungu $405 \mathrm{~nm}$ beserta sistem Hyperspctral Imaging.

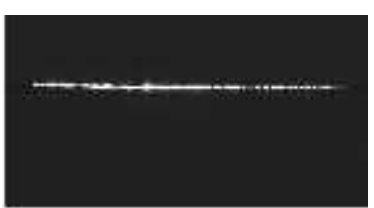

(a)

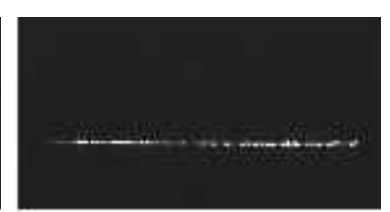

(b)
Gambar 4. (a) Citra laser dioda merah $650 \mathrm{~nm}$ (b) Citra laser dioda ungu $450 \mathrm{~nm}$

Citra hiperspektral yang dihasilkan oleh kamera CMOS terdiri dari sumbu y dan $\mathrm{x}$, dimana sumbu y mewakili jangkauan panjang gelombang spektrograf specim v10 yaitu 400 $\mathrm{nm}$ sampai dengan $1000 \mathrm{~nm}$. Citra cahaya laser $605 \mathrm{~nm}$ dan $405 \mathrm{~nm}$ seperti pada Gambar 4 mempunyai bentuk garis karena bersifat monokromatik dengan lebar pita panjang gelombang yang sempit,
Dua citra yang diperoleh dari proses kalibrasi kemudian ditentukan baris keberapa nilai intensitas maksimum dihasilkan. Nilai intensitas maksimum ditandai dengan perolehan nilai mariks yang bernilai 255 . Proses tersebut menunjukkan bahwa laser dioda merah $650 \mathrm{~nm}$ menghasilkan intensitas maksimum pada baris ke-388, dan laser dioda ungu $405 \mathrm{~nm}$ menghasilkan intensitas maksimum pada baris ke-671. Hasil tersebut kemudian digunakan untuk menentukan nilai panjang gelombang pada baris yang lainnya dengan menggunakan persamaan simple linear regression seperti yang terdapat pada Persamaan 1.

$\tilde{y}=\hat{\beta}_{0}+\hat{\beta}_{1} x$

$\hat{\beta}_{1}$ merupakan koefisien regresi yang diperoleh dengan menggunakan Persamaan 2 dan $\hat{\beta}_{\mathrm{U}}$ konstanta yang didapat dalam Persamaan 3 .

$\hat{\beta}_{1}=\frac{\sum_{i=1}^{n} y_{i} x_{i}-\frac{\left(\sum_{i=1}^{n} y_{l}\right)\left(\sum_{i=1}^{n} x_{i}\right)}{n}}{\sum_{l=1}^{n}\left(x_{i}-\bar{x}\right)^{2}}$

$\hat{\beta}_{0}=\bar{y}-\hat{\beta}_{1} \bar{x}$

Tahapan terakhir yaitu mendapatkan nilai intensitas reflektansi dari citra baru yang didapatkan dengan menggunakan algoritma yang terdapat pada program Matlab yang dibuat.

\section{HASIL DAN PEMBAHASAN}

Program GUI Matlab untuk mengolah citra hyperspectral telah berhasil dibuat. Program tersebut telah digunakan untuk menggabungkan setiap ukuran piksel baris dari 15 citra yang diperoleh dari satu sampel akar sehingga menghasilkan 1024 citra baru yang memiliki ukuran piksel $15 \times 1024$ dengan format BMP. Tampilan dari program GUI Matlab untuk citra akar diperlihatkan pada Gambar 3. 
Gambar 5 memperlihatkan citra hyperspectral akar yang diperoleh dengan menggunakan laser dioda. Citra akar yang disinari cahaya laser yang telah diperbesar diameter berkasnya tersebut menghasilkan pola garis lurus yang melebar dengan rentang panjang gelombang yang lebih lebar dibanding cahaya laser tanpa akar pada Gambar 4. Citra pada Gambar 4 dan 5 merupakan citra cahaya laser yang dipantulkan masing-masing oleh permukaan translation stage dan oleh akar yang disinari cahaya laser.

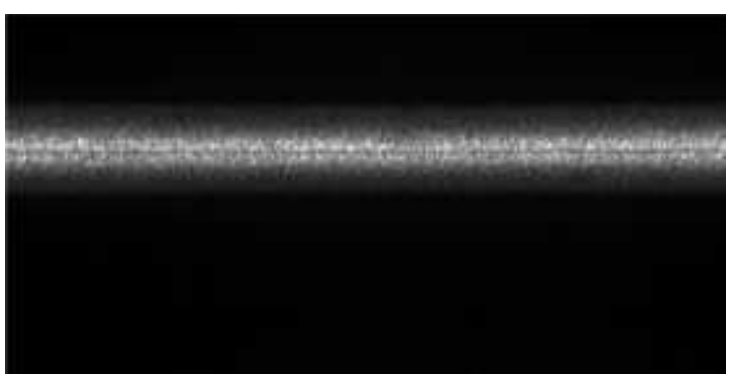

Gambar 5. Citra hyperspectral akar mengunakan laser dioda $650 \mathrm{~nm}$.

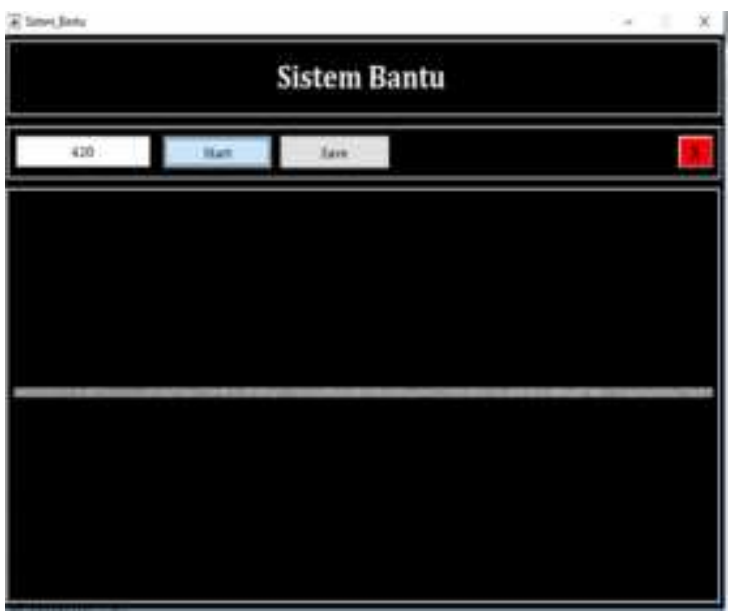

Gambar 6. Citra dari Matlab GUI.

Program Matlab GUI yang berhasil dibuat mempunyai beberapa fitur tombol untuk mengolah citra hyperspectral. Fitur tombol pertama digunakan untuk menggabungkan setiap piksel baris dari citra hyperspectral akar. Fitur tombol start digunakan untuk menjalankan program Matlab GUI untuk memproses citra yang akan digabungkan, sedangkan fitur tombol save berfungsi untuk menyimpan citra baru yang dihasilkan dari proses penggabungan ukuran piksel setiap baris yang dapat dilihat pada Gambar 6 .

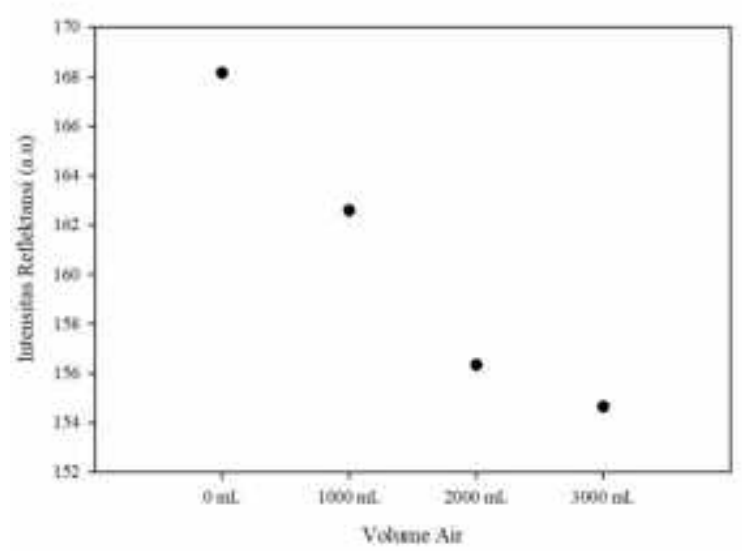

Gambar 7. Grafik hubungan intensitas reflektansi terhadap variasi volume air.

Gambar 7 merupakan grafik intensitas reflektansi terhadap volume air. Grafik menunjukkan bahwa semakin banyak pemberian volume air yang diberikan maka semakin rendah nilai intensitas reflektansi yang dihasilkan. Ini dapat disebabkan oleh berkurangnya kadar air pada bagian akar primer. Salah satu proses yang terjadi selama proses perlakuan cekaman kekeringan pada akar adalah penebalan lapisan epidermis pada akar. Proses penebalan lapisan epidermis pada akar bertujuan untuk meminimalisir proses terjadinya kehilangan air (Basu et al., 2016).

\section{KESIMPULAN}

Beberapa hal dapat disimpulkan dari penelitian ini yaitu program GUI Matlab yang dibuat menghasilkan citra baru sebanyak 1024 citra dengan ukuran piksel $15 \times 1280$. Program dapat digunakan untuk memper informasi nilai intensitas reflektansi. Nilai intensitas reflekansi yang dihasilkan oleh tanaman mengalami kekurangan air lebih tinggi dibandingkan dengan tanaman yang mendapakan pemberian air normal. Penelitian lanjutan dapat dilakukan pada cekaman yang lebih lama karena cekaman selama 21 hari 
belum memperlihatkan perubahan yang sangat signifikan.

\section{UCAPAN TERIMA KASIH}

Penulis mengucapkan terima kasih kepada BPDPKS yang telah membiayai sebagian penelitian ini melalui pengunaan spektrometer Specim V10 dan sistem pencitraan hiperspektral melalui grant riset sawit PRJ no 33. 2018

\section{DAFTAR PUSTAKA}

1. Houcque, D. 2005. Introduction to Matlab for Enginering students. Northwestern University. USA.

2. Qin, J., Burks, T. F., Kim, M. S., Chao, K., Ritenour, M. A. 2008. Citrus Canker Detection using Hyperspectral Reflectance Imaging and PCA-Based Image Classification Method. Sensing and Instrumentation for Food Quality and Safety.Vol 2(3):168-177.
3. Elmasry, G., Wang, N., Elsayed, A., Ngadi, M. 2007. Hyperspectra Imaging for Nondestructive Determination of Some Quality Attributes for Strawberry. Journal of Food Engineering. Vol 81: 98-107.

4. Sugiyama, J. and Tsuta, M. 2010. Visualization of Sugar Distribution of Melons by Hyperspectral Technique. Hyperspectral Imaging for Food Quality Analysis and Control. Vol 11: 349-368.

5. Henson, A. E., Roslan, M. N., Harun, M. M., Yahya, Z., Mustakim, S. N. 2005. Stress Development and its Detection in Young Oil Palm in North Kedah: Malaysia. Journal of Oil Palm Research. Vol 17:11-26.

6. Kramer, P. J. 1963. Water Stress and Plant Growth. Agro J. Vol 55 : 31- 35.

7. Basu, S., Ramegowda, V., Kumar, A. dan Pereira, A. 2016. Plant Adaptation to Drought Stress. F1000Research 2016, 5 :1554 